\title{
Therapeutic effects of new-type hydraulic delivery vertebroplasty, balloon kyphoplasty and conventional pusher-type vertebroplasty on single segmental osteoporotic vertebral compression fracture
}

\author{
PING ZHANG, ZHI-HONG ZHONG, HAO-TAO YU, WEI ZHOU and JIAN LI \\ Department of Orthopaedic, The Third Affiliated Hospital of Guangzhou Medical University, \\ Guangzhou, Guangdong 510000, P.R. China
}

Received January 11, 2018; Accepted July 31, 2018

DOI: $10.3892 /$ etm.2018.6624

\begin{abstract}
This study aims to evaluate safety and practicality in clinical application for better guidance of single segmental osteoporotic vertebral compression fractures treatment. From May 2012 to September 2013, a total of 188 cases of patients with fractures, who received different treatment, were incorporated in the study and then divided into: group A $(n=59)$, conventional pusher-type vertebroplasty; group B $(n=54)$, balloon kyphoplasty; group C $(n=60)$, new-type hydraulic delivery vertebroplasty treatment. The overall follow-up rate was $92.02 \%$. Postoperative visual analogue scale (VAS) and Oswestry disability index (ODI) scores were significantly improved more than those of the preoperative scores in the three groups. Bone cement injection volumes in group A were significantly lower than those in group B and group C. Vertebral height recovery rates among groups were obviously different, showing statistical significance. After a year of follow-up, the vertebral height recovery outcome in group A was obviously poorer than that in group B and group C. A poorer outcome in group B was also found when compared with group $\mathrm{C}$. In addition, the vertebral height restoration had a certain degree of loss, with the loss rate of $20.5,14.0$ and $7.5 \%$ in the three groups, respectively. Three operation methods have equivalent effects in the improvement of symptoms and functional recovery. Therefore, the new-type hydraulic delivery vertebroplasty provides a relatively more concise operation and shorter operation time, displaying more outstanding performance of clinical efficacy in spinal
\end{abstract}

Correspondence to: Dr Ping Zhang or Professor Jian Li, Department of Orthopaedic, The Third Affiliated Hospital of Guangzhou Medical University, 63 Duobao Road, Liwan, Guangzhou, Guangdong 510000, P.R. China

E-mail: srz2p9@163.com

E-mail: gmu3h_li@163.com

Key words: conventional pusher-type vertebroplasty, balloon kyphoplasty, new-type hydraulic delivery vertebroplasty, osteoporosis, vertebral compression fracture reconstruction and reduction of complications risks by evaluating the diffusion of the bone cement, vertebral height restoration rate and postoperative complications.

\section{Introduction}

By the end of the 21st century, the main demographic trends have been characterized with declining birth rates, stabilization in population size and elevation of the elderly population (1). The aging of the society is increasingly serious, and much attention has been paid for the prevention of common diseases and improvement of the quality of life of the elderly (2). It is anticipated that affected populations and corresponding health-care costs will be increased with population aging. Primary osteoporosis, associated osteoporotic compression fractures and a series of relevant complications are common in the elderly (in postmenopausal women predominantly, but also found in men) $(3,4)$. Osteoporotic vertebral compression fracture is a fragility fracture characterized by decreased in distal forearm, hip, femur and other parts $(5,6)$, most common in the spine (7). In the early years, frequent applicable approaches include bed rest, stent assisted living and daily activities and the use of anti-osteoporosis drugs. These measures are the most commonly used for the treatment of this condition $(7,8)$. However, such conservative treatment has failed to improve patients' severe pain and has always been accompanied by sleep disorders, mental anxiety and other symptoms, seriously affecting the quality of life of the patients $(9,10)$. Furthermore, long time physical dysfunction may not only lead to severe bone loss and increase the progression of osteoporosis, but also greatly improve risks of bedsore, related heart, lung complications, and elevated mortality rates in elderly patients during treatment.

The current treatment of osteoporotic vertebral compression fracture is designed to relieve pain, restore the activity of the elderly, and reduce the incidence of complications $(11,12)$. Vertebroplasty and kyphoplasty have been generally accepted and implemented $(13,14)$. Previous evidence has supported that vertebroplasty is less time-consuming and more cost-effective compared with kyphoplasty (15). Kyphoplasty is considered to be able to restore the vertebral height and reduce the risk of bone cement leakage (16). However, horizontal comparison of 
both methods has been widely debated. Initial vertebroplasty was performed with the use of a hollow tube and the push rod to inject bone cement into the vertebral body, which is simple and effective $(17,18)$. However, this metod is associated with a higher rate of bone cement leakage and recurrent fracture which is able to accurately control cement injection volume and injection pressure $(16,19)$. Many scholars have tried to improve the bone cement injection through other auxiliary devices, and new-type hydraulic delivery vertebroplasty is one of the valid methods. Through the hydraulic conveying bone cement injection device, precise control of bone cement injection dosage and injection pressure restriction can be achieved successfully, as well as the decreased risk of bone cement leakage $(20,21)$. Yet there were few relevant studies on the clinical application of those methods in the treatment of osteoporotic vertebral compression fractures.

Under the establishment of single segmental osteoporotic compression fractures, a comparative analysis was performed regarding the curative effect, physiological structure recovery, and common complication rates such as bone cement leakage of conventional pusher-type vertebroplasty, balloon kyphoplasty and new-type hydraulic delivery vertebroplasty in the treatment of single segmental osteoporotic vertebral compression fractures, so as to evaluate corresponding safety and practicality in clinical application for better guidance for the treatment of such kind of disease.

\section{Materials and methods}

Ethical statement. All procedures performed in studies involving human participants were in accordance with the ethical standards and with the 1964 Helsinki declaration and its later amendments or comparable ethical standards. Before enrollment, written informed consents were provided from each participant before the performance of the experiment, which involved the informing of the risk of treatment procedures. The study was approved by the Ethics Committee of the Third Affiliated Hospital of Guangzhou Medical University (Guangzhou, China).

General information. The study was performed based on the incorporation of osteoporotic vertebral compression fracture patients who had operative indications in the Third Affiliated Hospital of Guangzhou Medical University from May 2012 to September 2013. Following screening and excluding, only patients with single segmental osteoporotic vertebral compression fractures were included in the study to avoid the mutual influence of multi-segment compression fractures in the evaluation and statistical analysis for the curative effect.

Inclusion criteria were: i) patients who were positively diagnosed with single segmental osteoporotic vertebral compression fractures in combination with clinical symptoms and signs, X-ray film, and/or magnetic resonance imaging; ii) symptoms appearing within 2 weeks and the magnetic resonance imaging results were confirmed with fresh fracture; iii) vertebral compression which did not exceed $75 \%$; iv) spinal compression fractures without causing symptoms of nerve compression; v) patients without severe mental or neurological disorders, cardiac and pulmonary dysfunction, or other disorders that may affect the outcome of surgery or postoperative recovery; vi) patients who did not suffer from femoral head necrosis, severe knee arthritis and other walking activities that may affect the postoperative recovery of the disease, and vii) operative indications covering the following aspects: Vertebral compression exceeded $1 / 2$ of the vertebral body; angle of kyphosis over $30^{\circ}$; $1 / 3$ intraspinal occupying; obvious symptoms of vertebral instability; severe osteoporotic vertebral fractures, and invalid conservative treatment.

Exclusion criteria were: i) imaging results showed compression fracture in the fifth thoracic vertebral body and above, but unclear during intraoperative X-ray imaging since the lateral film was covered by the shoulder blade; ii) patients who had poor blood pressure control during operation, or who were weak and unable to keep pronation, as well as those patients who had bone cement allergies or other situation that needed to suspend the operation; iii) patients with symptoms such as femoral head necrosis, severe knee arthritis and other walking activities, which may affect the postoperative recovery of the disease; iv) patients who had postoperative complications of bleeding, infection, coagulation disorders and other disorders affecting the normal course of treatment, and v) patients who were unable to cooperate with the postoperative treatment or to adhere to 1 year-follow-up due to economic or other medical reasons.

In strict accordance with the preset selection criteria, the study was designed by prospective investigation. There were a total of 188 cases of patients who were finally incorporated in this cohort study, with a sum up of 259 segments. Enrolled patients were classified into three groups by using stratified-block randomized grouping method on the basis of sex distribution, as well as affected/operated segments distributions and positions. Patients were blinded to the study and were unaware of the treatment assignment: i) group A, conventional pusher-type vertebroplasty was carried out in 63 cases of patients with 90 segments within this group; ii) group B, patients in this group were managed by balloon kyphoplasty, and a total of 58 cases of 81 segment were involved in; iii) group C, patients in this subgroup received a new-type hydraulic delivery vertebroplasty treatment, and there were 67 patients with 95 segments. Before operation, the vertebroplasty and kyphoplasty groups had similar baseline back pain based on the SF-36 physical component summary and Oswestry disability index (ODI) scores assessment. After operation, all patients received appropriate postoperative care, rehabilitation exercise and guidance for the treatment of osteoporosis.

Follow-up information. In this study, the follow-up period lasted 12 months after operation. At the end of the study, a total of 15 patients were excluded from this study due to the exclusion criteria of the cohort study; 4 of which showed blood pressure fluctuations during operation and could not tolerate surgery and were further excluded from this study; 4 patients with underlying disease progression during the follow-up period were excluded from the study. Additionally, 7 patients were lost during the follow-up period. Finally, a total of $59(59 / 63,93.65 \%)$ patients were involved and completed the study process in group A; $54(54 / 58,93.10 \%)$ patients completed the study process in group B; $60(60 / 67,89.55 \%)$ patients finished the study process in group $\mathrm{C}$. The overall follow-up rate was $92.02 \%$. 
A

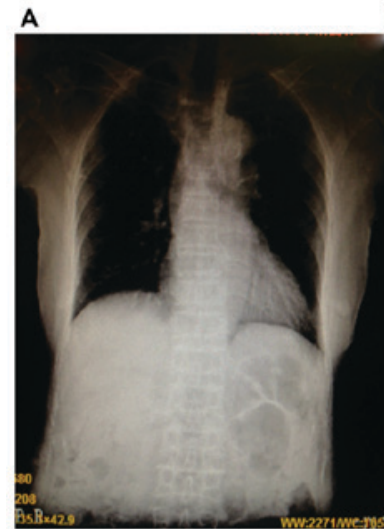

B

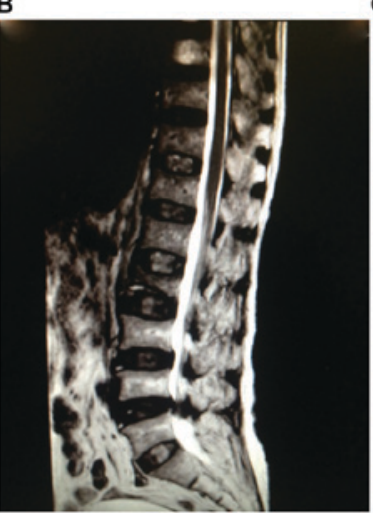

E

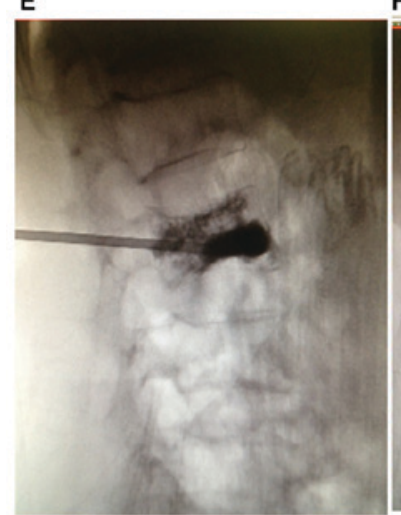

F
C

c
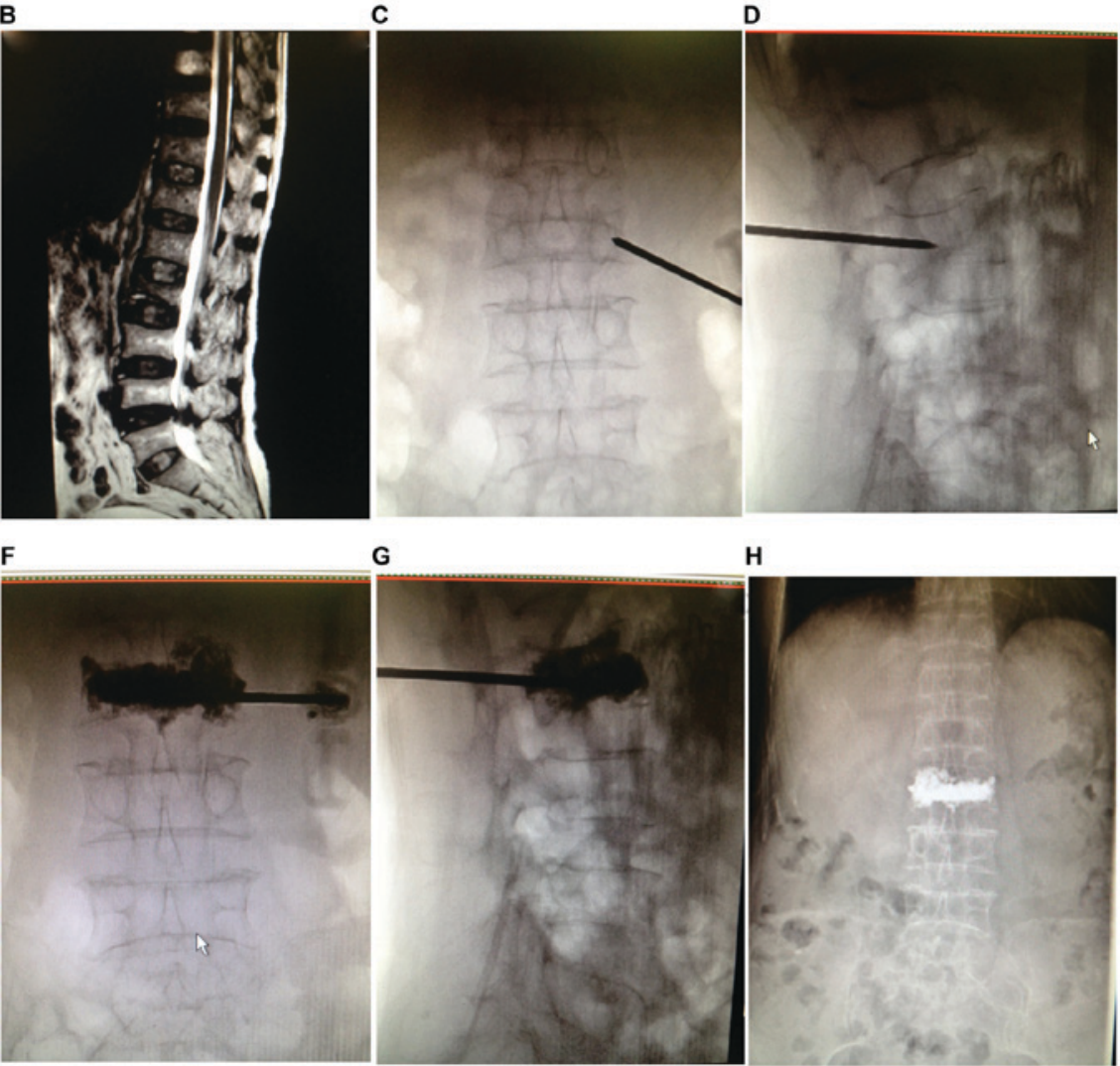

G
H

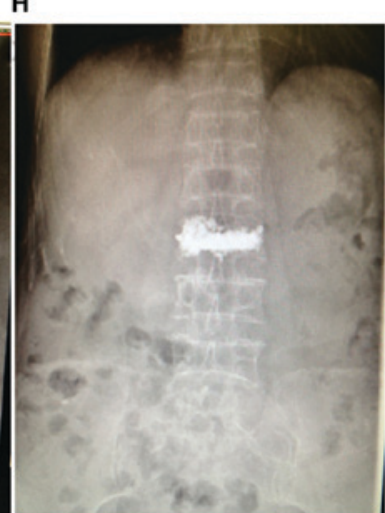

Figure 1. Typical images of patients and correlated surgical procedures of conventional pusher-type vertebroplasty. Eight images were collected from the results of digital image examination in the Radiology Department. (A and B) Imaging of the lumbar vertebra and the chest of the patient. (C-H) Surgical procedures of conventional pusher-type vertebroplasty step by step. The hollow push pipes were filled with bone cement, along the puncture needle, and the pipes were inserted and pushed into bone cement until the bone cement was diffused bilaterally and infiltration to posterior parts of the vertebral bodies under the monitoring of the X-ray intermittent fluoroscopy occurred.

\section{Operative procedures}

General information and procedures within the three groups. The use of bone cement was the production of PMMA MENDECSpine low viscosity bone cement in Italy (Tecres S.P.A., Sommacampagna, Italy). Surgical instruments were purchased from Shanghai kailitai medical Polytron Technologies Inc. (Shanghai, China). For three kinds of operation, patients were informed to take the prone position in the surgical bed. Sterile surgical towel, was used and foundation as well as sedative drugs were given to relieve patients' anxiety. Surgery was conducted by unilateral approach, and the side of the patient with conscious pain was selected as the choice of surgical approach, following a $2 \%$ lidocaine local anesthesia. Using a percutaneous procedure, the needle was inserted in the direction of the pedicle of vertebral arch (depending on different segments), and was adjusted under the guidance of X-ray. The needle in the lateral spine development was confirmed to be located in the pedicle of the vertebral arch, and entered into the anterior-inferior $1 / 3$ part along the pedicle of vertebral arch. In order not to penetrate the inner wall of the pedicle in the spinal normal development, the needle orientation was kept at an approximately 10-15 abduction angle, and it was ensured that the tip was as close to the midline of the vertebral body as possible. Subsequently, following another confirmation of the proper location of the puncture under fluoroscopic guidance, the needle core was pulled out. Furthermore, after the finishing of operational procedures in three groups, the operation time, number of operations, as well as operation symptoms in the course of all enrolled surgical patients were accurately recorded.

Conventional pusher-type vertebroplasty. Typical images of patients and correlated surgical procedures of conventional pusher-type vertebroplasty are shown in Fig. 1. The equal proportion of bone cement powder and liquid mixture were poured into the mixing bowl, and cement was mixed into the early stage of the wire drawing under rapid agitation. The hollow push pipes were filled with bone cement $(0.75 \mathrm{ml} / \mathrm{pipe})$. Along the puncture needle, the pipes were inserted and pushed into bone cement until bone cement was diffused bilaterally and infiltration to posterior parts of the vertebral bodies under the monitoring of the X-ray intermittent fluoroscopy occurred. Of note, injection was stopped immediately if there was an occurrence of bone cement leakage of the vertebral body before satisfactory infiltration dispersion was reached. The above process was controlled within $10 \mathrm{~min}$ after the bone cement mixture had been completed. If the bone cement mixture had set within 15 min or full hardening of the residual bone cement occurred, the puncture needle was pulled out, followed by surgical dressing covering, and then the operation was completed.

Balloon kyphoplasty. The size of dilation balloon was 15 or $20 \mathrm{~mm}$ according to the size of the patient's injury. The puncture needle was preset to be inserted into the vertebral body $1 / 3$ part, and the specific position was determined according to 
A

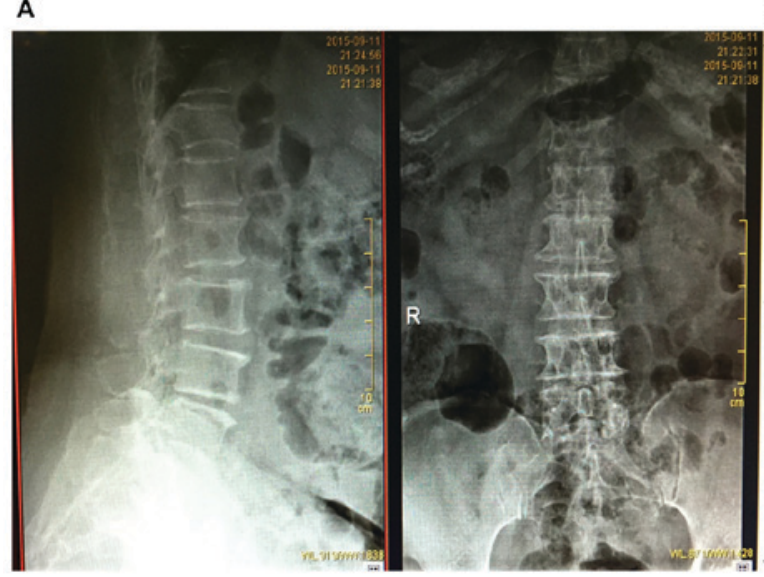

C

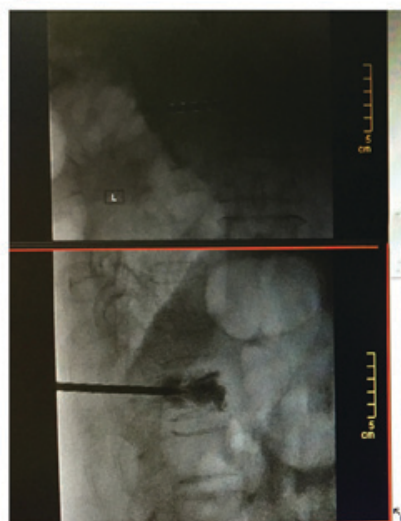

B

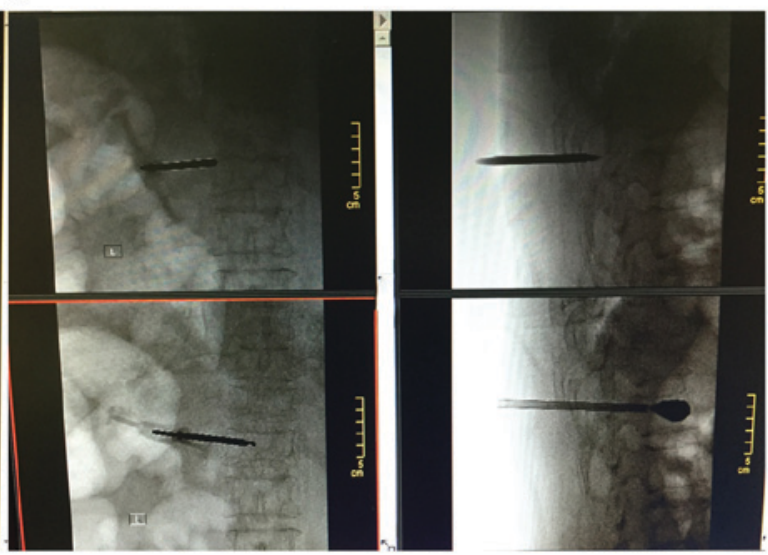

D

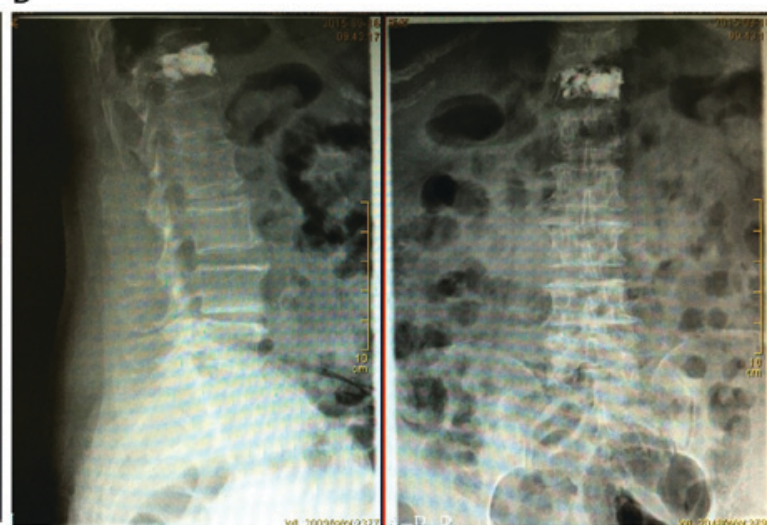

Figure 2. Typical images of patients and related surgical procedures of balloon kyphoplasty. There were a total of four images which were collected from the results of digital image examination in the Radiology Department. (A) Imaging of the lumbar vertebra of the patient. (B-D) Surgical procedures of balloon kyphoplasty step by step. The puncture needle was preset to be inserted into the vertebral body $1 / 3$ part, the guide wire was placed from the outside of the needle tube, and the dilator was inserted under the guidance of the guide wire to establish a working channel. The dilation balloon was inserted via the working channel.

the size of the vertebral injury and the size of dilation balloon. The guide wire was placed from the outside of the needle tube, and the dilator was inserted under the guidance of the guide wire to establish a working channel. Fine bone drill was used to drill into the vertebral body $1 / 3$ part, and then the bone drill and vertebral body bone fragments were removed. The dilation balloon was inserted via the working channel, and it was confirmed that the balloon front did not damage the vertebral body wall nor the trailing edge beyond the outer tube of the puncture needle by the monitoring of the X-ray intermittent fluoroscopy. After opening the tee valve, injection of contrast agent was performed in 15 atmospheric pressure to dilate the balloon, and the balloon was evacuated after dilation was satisfactorily achieved after which the catheter was removed. The equal proportion of bone cement powder and liquid mixture were poured into the mixing bowl, and cement was mixed into the early stage of the wire drawing. Subsequent procedures were the same as those in group A (steps 1-5), followed by a surgical dressing covering, indicating the operation in group $\mathrm{B}$ was finished. Typical images related to the surgical procedures are presented in Fig. 2.

New-type hydraulic delivery vertebroplasty. On the operating table, a 20-ml sterile saline extracted with a syringe was injected into the hydraulic cylinder to $0^{\circ}$ of the water level calibration line, and then, the hydraulic cylinder back cover was tightened. The equal proportion of bone cement powder and liquid mixture were poured into the mixing bowl, and cement was mixed into the early stage of the wire drawing. Cylinder-connected injection tube was inverted and pressed into the mixing drum, followed by clockwise rotation of the inverted barrel collar, and stirring barrel of bone cement was transferred to the injection tube. When the cylinder was arranged, the counter rotating cylinder was rotated clockwise to take down the cylinder and the mixing drum, and the quick joint of the hydraulic cylinder was inserted into the back cover of the injection tube. The syringe and needle tip were bolted down jointly. Clockwise rotation of the hydraulic cylinder pushed the handle and bone cement in the injection tube was slowly injected into the injured vertebra $(0.3 \mathrm{ml} /$ circle $)$. The bone cement was injected into the posterior part of the bone cement through the monitoring of X-ray, and the posterior part of the vertebral body was diffused and infiltrated to the posterior part of the bone cement. The above process was controlled within $10 \mathrm{~min}$ after bone cement mixture was completed. Once the bone cement mixture had set for 15 min or full hardening of the residual bone cement occurred, the puncture needle was pulled out, followed by surgical dressing covering, and then the operation was completed. Details of the new-type hydraulic delivery vertebroplasty typical images of patients 
A

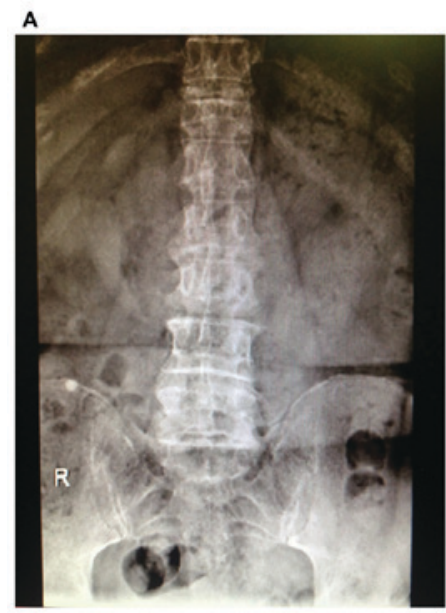

B

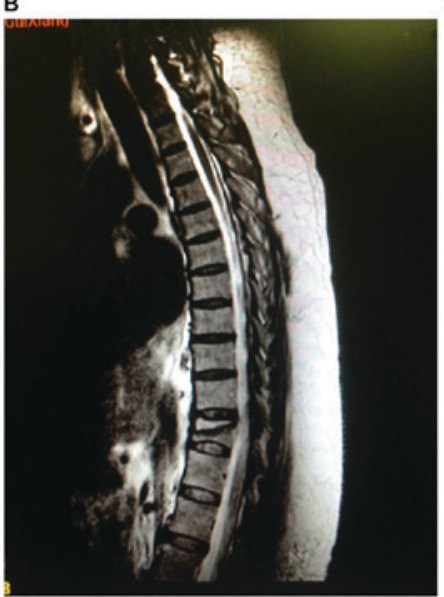

E

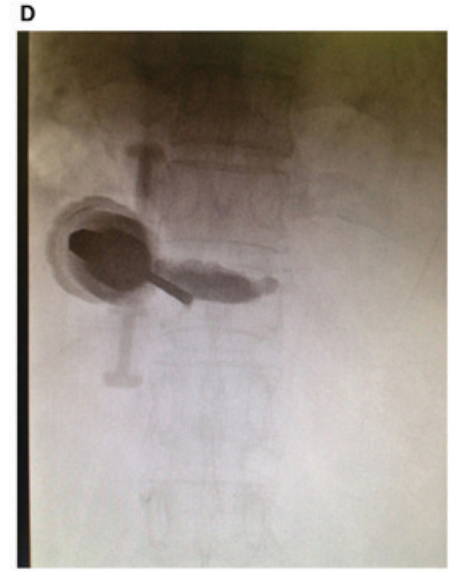

c

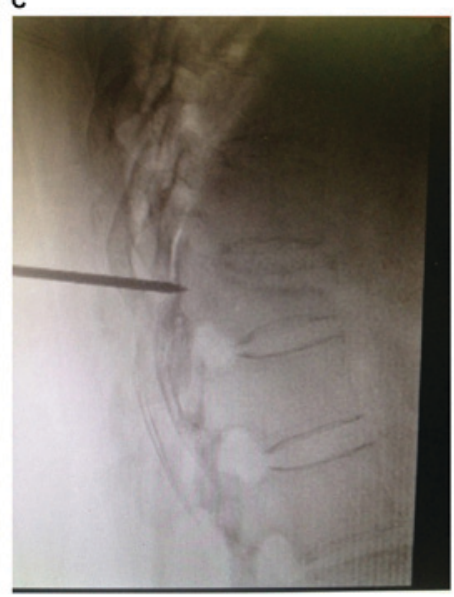

F

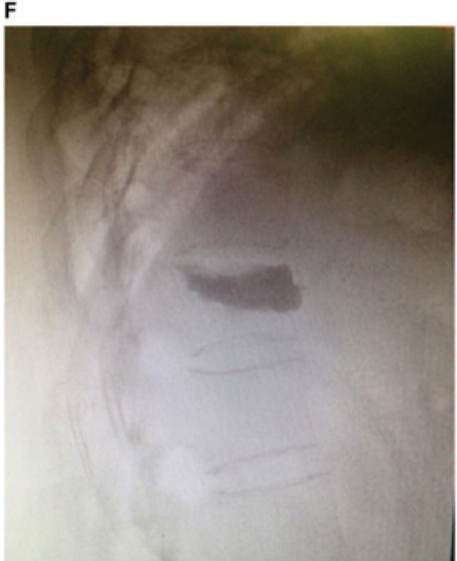

Figure 3. Typical images of patients and correlated surgical procedures of the new-type hydraulic delivery vertebroplasty. Six images were collected from the results of digital image examination in the Radiology Department. (A and B) Imaging of the lumbar vertebra of the patient. (C-F) Surgical procedures of new-type hydraulic delivery vertebroplasty. Bone cement in the injection tube was slowly injected into the injured vertebra. The bone cement was injected into the posterior part of the bone cement through monitoring of X-ray and the posterior part of the vertebral body was diffused and infiltrated to the posterior part of the bone cement.

and correlated surgical procedures conducted step by step are shown in Fig. 3.

Evaluation of therapeutic effect. Before surgery, 1 day after the operation, one month and six months after surgery, visual analogue scale (VAS) was used to compare the degree of pain in patients, respectively (22). Corresponding scoring standards were as follows: 0 point for painless, 10 points for intolerable pain. Oswestry dysfunction indexes (ODI) (23) were used for functional recovery assessment. Height of the center, vertebral body and percentage of restoration in the vertebral body height were calculated subsequently to measure the stability of the structure. The incidence of bone cement leakage was recorded, and the risk of surgical complications were further compared.

Statistical analysis. SPSS version 22.0 software (IBM Corp., Armonk, NY, USA) was used. The age, sex ratio, operation time and bone cement injection volume of different groups were verified by single factor analysis of variance followed by post hoc test (Least Significant Difference). The VAS score, ODI score and incidence of bone cement leakage was verified by t-test before and after surgery. The percentage of restoration in the vertebral body height was verified by the Wilcoxon rank-sum test, and the difference was statistically significant when $\mathrm{P}<0.05$.

\section{Results}

General data comparison among the three groups. There were 59 cases of patients with 85 segments within group A. A total of 54 cases of 75 segment were involved in group B, and 60 patients with 88 segments in group C. Corresponding affected/operated segments of participants from each procedure are provided in Table I, primarily concentrated in the area of the thoracolumbar segments. Mean ages of subjects from each group were $61.36 \pm 11.76,59.73 \pm 10.71$ and $64.38 \pm 12.00$ years old, respectively. The sex ratios (male/female) of each group were 14/49,11/47 and 16/51, respectively. No significant statistical difference was found regarding age and sex among the three groups, suggesting a comparability in those groups to some extent (all $\mathrm{P}>0.05$ ). Furthermore, there was no statistical significance in the operation time between group A and group C, but there were statistical differences in that the operation time in group B was obviously higher than that in groups $\mathrm{A}$ and $\mathrm{C}($ all $\mathrm{P}<0.05)$. In addition, considering the comparison of VAS and ODI scoring results before and after surgery, as shown in Table I, VAS and ODI scores were significantly lower preoperatively than those postoperatively among the three groups (all $\mathrm{P}<0.05)$. However, there was no statistical difference in the comparison of different 
Table I. Baseline characteristics and the results of VAS and ODI scores before and after surgery among groups.

\begin{tabular}{|c|c|c|c|c|c|}
\hline Variables & $\begin{array}{c}\text { Group A } \\
(\mathrm{n}=59)\end{array}$ & $\begin{array}{c}\text { Group B } \\
(\mathrm{n}=54)\end{array}$ & $\begin{array}{c}\text { Group C } \\
(\mathrm{n}=60)\end{array}$ & $\mathrm{F} / \chi^{2}$ & P-value \\
\hline Age (years) & $61.36 \pm 11.76$ & $59.73 \pm 10.71$ & $64.38 \pm 12.00$ & 2.409 & 0.093 \\
\hline Sex (male/female) & $12 / 47$ & $11 / 43$ & $13 / 47$ & & 0.980 \\
\hline Affected/operated segments & & & & 0.261 & 0.992 \\
\hline Upper-middle thoracic vertebrae (T4-T9) & 26 & 21 & 26 & & \\
\hline Thoracolumbar (T10-L2) & 46 & 44 & 51 & & \\
\hline Lower lumbar vertebrae (L3-L5) & 18 & 16 & 18 & & \\
\hline Operation time & $24.50 \pm 4.30$ & $32.60 \pm 5.00^{\mathrm{a}}$ & $25.40 \pm 3.80^{\mathrm{b}}$ & 54.77 & $<0.0001$ \\
\hline \multicolumn{6}{|l|}{ VAS score } \\
\hline Before surgery & $8.10 \pm 2.40$ & $8.10 \pm 2.50$ & $8.20 \pm 2.20$ & 0.035 & 0.966 \\
\hline 1 day after surgery & $2.60 \pm 0.30$ & $2.30 \pm 0.40^{\mathrm{a}}$ & $2.20 \pm 0.40^{\mathrm{a}}$ & & $<0.0001$ \\
\hline 1 month after surgery & $1.70 \pm 0.30$ & $1.80 \pm 0.20$ & $1.50 \pm 0.10^{\mathrm{a}, \mathrm{b}}$ & 18.80 & $<0.0001$ \\
\hline 6 months after surgery & $1.50 \pm 0.20$ & $1.40 \pm 0.30$ & $1.40 \pm 0.20^{\mathrm{a}}$ & 3.497 & 0.033 \\
\hline \multicolumn{6}{|l|}{ ODI score } \\
\hline Before surgery & $78.24 \pm 13.07$ & $77.52 \pm 12.27$ & $78.12 \pm 12.83$ & 0.051 & 0.950 \\
\hline 1 day after surgery & - & - & - & & \\
\hline 1 month after surgery & $34.55 \pm 8.77$ & $32.14 \pm 10.10^{\mathrm{a}}$ & $35.27 \pm 11.35$ & 1.465 & 0.234 \\
\hline 6 months after surgery & $26.30 \pm 7.11$ & $26.68 \pm 6.91$ & $25.89 \pm 8.78$ & 0.151 & 0.860 \\
\hline
\end{tabular}

VAS, visual analogue scale; ODI, Oswestry dysfunction indexes. ${ }^{\mathrm{a} G r o u p ~ A ~ c o m p a r e d ~ w i t h ~ g r o u p s ~ B ~ a n d ~ C, ~ r e s p e c t i v e l y, ~} \mathrm{P}<0.05$. ${ }^{\mathrm{b}}$ Group B compared with group C, $\mathrm{P}<0.05$.

time-point before and after operation within the three groups (all $\mathrm{P}>0.05)$.

Total vertebral compression rates comparison among the three groups. As shown in Table II, the total vertebral compression rate of groups A and B was $43.31 \pm 8.93$ and $43.17 \pm 6.66 \%$ respectively, compared with group $\mathrm{C}(45.24 \pm 7.86 \%)$, and there was no significant difference among the three groups $(\mathrm{P}>0.05)$. Furthermore, the bone cement injection volumes in group A were significantly lower than those in groups B and C, with statistical significance (both $\mathrm{P}<0.05$ ). Yet there was no significant difference between group $\mathrm{B}$ and group $\mathrm{C}(\mathrm{P}>0.05)$. One day after the operation, the vertebral height recovery rates were $20.11 \pm 5.34,28.47 \pm 3.36$ and $32.17 \pm 3.20 \%$ in groups $\mathrm{A}, \mathrm{B}$ and $\mathrm{C}$, respectively, showing statistical differences (all $\mathrm{P}<0.05$ ). After a year of follow-up, the vertebral height recovery rate of the three groups were $16.14 \pm 3.33$, $26.24 \pm 2.12$ and $29.82 \pm 5.13 \%$, respectively. The vertebral height recovery outcome in group A was obviously poorer than that in groups $\mathrm{B}$ and $\mathrm{C}$ (both $\mathrm{P}<0.05$ ). Furthermore, a poorer outcome in group $\mathrm{B}$ was also found when compared with group $\mathrm{C}(\mathrm{P}<0.05)$. A year and one day after operation, X-ray films showed the vertebral height restoration had certain degree of loss, and compared with the recovery degree results, the loss rate was $20.5,14.0$ and $7.5 \%$ in groups $\mathrm{A}, \mathrm{B}$ and $\mathrm{C}$, respectively, while obviously lower in group $\mathrm{C}$.

Bone cement dispersion comparison among the three groups. $\mathrm{X}$-ray was applied in the included patients to confirm whether bone cement was over midline and reached the opposite side more than $3 / 4$ of the vertebral body or not, and bone cement dispersion of the three different operative treatments was classified into three levels, namely, satisfactory, unsatisfactory and poor. There were 12 cases of poor dispersion and 20 cases of unsatisfactory dispersion in group A. Furthermore, in group B, 9 cases of poor dispersion were found, and no cases of unsatisfactory dispersion. In group $\mathrm{C}$, there were 8 cases of poor dispersion and no case of unsatisfactory dispersion. In comparison, the bone cement dispersion in groups $\mathrm{B}$ and $\mathrm{C}$ were relatively better than that in group A, with a statistical difference (both $\mathrm{P}<0.05$ ). A lower bone cement dispersion rate was also found in group $\mathrm{C}$ when compared to that in group $\mathrm{B}$.

Follow-up and postoperative complications comparison. There were no complications such as vascular embolization, spinal cord compression and other serious bone cement leakage during the follow-up period of 1 year among the three groups. There were a total of 17 segments showing bone cement leakage event that had no symptoms or caused local mild symptoms: 7 segments were in group A $(7 / 59,11.86 \%), 6$ segments in group B $(6 / 54,11.11 \%)$ and 4 segments in group C $(4 / 60,6.67 \%)$. There were 8 cases of primary vertebral fractures, adjacent vertebral fractures or other vertebral compression fractures in 1 year after the operation with 3 cases in group A, 4 cases in group $\mathrm{B}$, and 1 case in group $\mathrm{C}$, while group $\mathrm{C}$ was significantly lower (Table III). In particular, 8 patients with recurrent spinal fractures in one year after surgery were the same as those with diffuse or poor dispersion. This may indicate that there was a 
Table II. The total vertebral compression and vertebral height recovery rate comparison among the three groups.

\begin{tabular}{|c|c|c|c|c|}
\hline Variables & $\begin{array}{c}\text { Group A } \\
(\mathrm{n}=59)\end{array}$ & $\begin{array}{c}\text { Group B } \\
(\mathrm{n}=54)\end{array}$ & $\begin{array}{c}\text { Group C } \\
(\mathrm{n}=60)\end{array}$ & P-value \\
\hline Preoperative vertebral compression rate $(\%)$ & $43.31 \pm 8.93$ & $43.17 \pm 6.66$ & $45.24 \pm 7.86$ & 0.288 \\
\hline Bone cement injection volume (ml) & $3.41 \pm 1.30$ & $4.60 \pm 1.00^{\mathrm{a}}$ & $4.40 \pm 0.90^{\mathrm{a}}$ & $<0.0001$ \\
\hline \multicolumn{5}{|l|}{ Vertebral height recovery rates $(\%)$} \\
\hline 1 day after surgery & $20.11 \pm 5.34$ & $28.47 \pm 3.36^{\mathrm{a}}$ & $32.17 \pm 3.20^{\mathrm{a}, \mathrm{b}}$ & $<0.0001$ \\
\hline 1 year after surgery & $16.14 \pm 3.33$ & $26.24 \pm 2.12^{\mathrm{a}}$ & $29.82 \pm 5.13^{\mathrm{a}, \mathrm{b}}$ & $<0.0001$ \\
\hline Height restoration loss rate $(\%)$ & 20.3 & 14.8 & 8.3 & $<0.0001$ \\
\hline
\end{tabular}

${ }^{\mathrm{a}}$ Group A compared with groups B and C, respectively, $\mathrm{P}<0.05$; ${ }^{\mathrm{b}}$ Group B compared with group C, $\mathrm{P}<0.05$.

Table III. Postoperative complications classification and comparison among the three groups.

\begin{tabular}{|c|c|c|c|c|}
\hline Complications & Types & $\begin{array}{c}\text { Group A } \\
(\mathrm{n}=59) \\
\mathrm{n}(\%)\end{array}$ & $\begin{array}{c}\text { Group B } \\
(\mathrm{n}=54) \\
\mathrm{n}(\%)\end{array}$ & $\begin{array}{c}\text { Group C } \\
(\mathrm{n}=60) \\
\mathrm{n}(\%)\end{array}$ \\
\hline \multirow[t]{3}{*}{ Bone cement leakage event } & Peripheral vertebral leakage & $1(1.7)$ & $0(0)$ & $0(0)$ \\
\hline & Posterior vertebral leakage & $3(5.0)$ & $4(7.4)$ & $2(3.3)$ \\
\hline & Needle tract leakage & $3(5.0)$ & $2(3.7)$ & $2(3.3)$ \\
\hline \multirow[t]{3}{*}{ Recurrent spinal fractures } & Primary vertebral fractures & $1(1.7)$ & $0(0)$ & $0(0)$ \\
\hline & Adjacent vertebral fractures & $0(0)$ & $2(3.7)$ & $0(0)$ \\
\hline & Other vertebral compression fractures & $2(3.4)$ & $2(3.7)$ & $1(1.7)$ \\
\hline
\end{tabular}

certain correlation between the dispersion of bone cement and the high risk of re-fracture.

\section{Discussion}

In the study, the curative efficacy of conventional pusher-type vertebroplasty, balloon kyphoplasty and new-type hydraulic delivery vertebroplasty were compared in the treatment of single segment osteoporotic vertebral compression fractures, to evaluate the remission of symptoms, functional recovery, reconstruction and prognosis assessment and thus to investigate the safety and practicality correspondingly. All the incorporated subjects were comparable among the three groups. Besides, enrolled patients were confirmed with single segmental osteoporotic vertebral compression fractures and underwent strict inclusion and exclusion criteria to avoid possible selection bias and potential interactions of mixed multiple segmental fracture affecting therapeutic effects assessment and statistical analyses. Additionally, thoracolumbar segments of the middle spinal are the transition segment of the thoracic kyphosis to the lumbar lordosis, upper undertaking of a relatively stable thoracic spine, lower connecting of the lower lumbar vertebrae with a relatively strong structure and supported by pelvis, which is the turning point in the flexion position of spinal biomechanics, and fracture is therefore frequent by external force.

In the comparison of pain relief related index VAS score and functional recovery index ODI score, VAS and ODI scores were significantly lower preoperatively than those postoperatively among the three groups, yet no statistical difference was observed comparing different time-points before and after operation within the three groups. The aforementioned results suggested that all approaches could significantly improve the postoperative VAS and ODI scores, providing similar sustained improvement with regard to pain and quality of life from baseline and remaining stable during the follow-up. These improvements were statistically significant and indicated certain clinical value regarding pain relief and functional recovery. Yet, neither balloon kyphoplasty nor the new-type hydraulic delivery vertebroplasty displayed their superiority. However and most importantly, it is not sufficient to simply evaluate the pain alleviation or short-term functional recovery to comprehensively evaluate the therapeutic effect of osteoporotic vertebral compression fractures. Vertebral body structure stability plays an important role in the long-term guarantee of the quality of life of patients after operation (24). Further investigation on postoperative recovery and complication rates supported the significance of the new-type hydraulic delivery vertebroplasty in the treatment of single segmental osteoporotic vertebral compression fracture treatment.

Bone cement dispersion has been considered to be a critical index in the evaluation of the treatment efficacy of vertebroplasty and kyphoplasty (25-27). Bonecement dispersion and distribution of the hydraulic delivery vertebroplasty had been indicated to be a more ideal selection than that of the conventional pusher-type vertebroplasty or balloon kyphoplasty, which may also have a positive correlation with the stability of the vertebral body and risk of complications 
postoperatively. Furthermore, after a year of follow-up, results of the height of the vertebral body also reflected the advantages of the new-type hydraulic delivery vertebroplasty. Both the bone cement injection volume and recovery rate of vertebral body height postoperatively were compared, and the result of the hydraulic delivery vertebroplasty group was better than that of the conventional pusher-type vertebroplasty group or balloon kyphoplasty group. Particularly noteworthy was that one year after surgery, the recovery vertebral body height still appeared significantly higher level in the patients of the hydraulic delivery vertebroplasty group than that of the other two groups. This may be likely to be a high-risk factor for the subsequent fracture of the vertebral body or other vertebral bodies of the latter two procedures, which may also be closely related to the dispersion of the bone cement (28).

Furthermore, although more bone cement injection was found in the hydraulic delivery vertebroplasty group than that in the conventional pusher-type vertebroplasty group or balloon kyphoplasty group. The leakage rate of the bone cement in the former group did not increase and was even lower than the latter two groups. Similar results were also found regarding complications such as the recurrence of spine fracture, although the follow-up time was relatively short, and the sample size was small. At least, this part of the investigation proved the stability and security of the new-type hydraulic delivery vertebroplasty in the management of osteoporotic vertebral compression fractures. In addition, a relatively higher bone cement leakage rate was found in the conventional pusher-type vertebroplasty group than that in the other two groups, and a possible reason may be that in the process of injection of the bone cement, the loading of vertebral pressure would inevitably result in the whole structure damage of the original vertebral bone structure. If the bone cement dispersion outcome was poor, the support effect would not be ideal, and bearing unevenness would therefore cause loss of vertebral height and increased refracture risk (28-30).

The major limitation in this study was the relatively smaller sample size and relatively shorter follow-up period, which may affect the statistical power of the results. Furthermore, there is still no established standard for vertebroplasty and kyphoplasty. However, health-care in the perioperative period were kept in consistent. Of note, the strengthening of this study lies in the detailed selection criteria aimed to reduce selection bias, and the results of this trial confirmed the effectiveness of the new-type hydraulic delivery vertebroplasty at index levels was correlated with physical examination, imaging findings and postoperative follow-up. It will be better to verify the current study with further multicenter, large sample size and long-term follow-up studies.

To sum up, three operation methods have equivalent effects in the improvement of symptoms and functional recovery. Significantly, new-type hydraulic delivery vertebroplasty has a more concise operation and shorter operation time, displaying more outstanding treatment outcomes in the spinal reconstruction and reduction of complications by evaluating the diffusion of the bone cement, vertebral height restoration rate and postoperative complications than conventional pusher-type vertebroplasty and balloon kyphoplasty.

\section{Acknowledgements}

Not applicable.

\section{Funding}

No funding was received.

\section{Availability of data and materials}

The datasets used and/or analyzed during the present study are available from the corresponding author on reasonable request.

\section{Authors' contributions}

PZ and JL designed the study. ZHZ and HTY collected the patient data. WZ analyzed the patient data. PZ prepared the manuscript. All authors read and approved the final manuscript.

\section{Ethics approval and consent to participate}

The study was approved by the Ethics Committee of the Third Affiliated Hospital of Guangzhou Medical University (Guangzhou, China). Signed written informed consents were obtained from the patients and/or guardians.

\section{Patient consent for publication}

Not applicable.

\section{Competing interests}

The authors declare that they have no competing interests.

\section{References}

1. DESA: World Population Prospects: The 2012 Revision. Population Division of the Department of Economic and Social Affairs of the United Nations Secretariat, New York, 2013.

2. Harper S: Economic and social implications of aging societies. Science 346: 587-591, 2014.

3. Bliuc D, Alarkawi D, Nguyen TV, Eisman JA and Center JR: Risk of subsequent fractures and mortality in elderly women and men with fragility fractures with and without osteoporotic bone density: The Dubbo Osteoporosis Epidemiology Study. J Bone Miner Res 30: 637-646, 2015.

4. Fernández-Ruiz M, Guerra-Vales JM, Trincado R, Medrano MJ, Benito-León J and Bermejo-Pareja F: Hip fracture in three elderly populations of central Spain: Data from the NEDICES study. Intern Emerg Med 9: 33-41, 2014.

5. Svensson HK, Olofsson EH, Karlsson J, Hansson T and Olsson LE: A painful, never ending story: Older women's experiences of living with an osteoporotic vertebral compression fracture. Osteoporos Int 27: 1729-1736, 2016.

6. Stauff MP and Carragee EJ: Vertebral compression fracture rules. Spine J 14: 971-972, 2014.

7. Sinaki M: Yoga spinal flexion positions and vertebral compression fracture in osteopenia or osteoporosis of spine: Case series. Pain Pract 13: 68-75, 2013.

8. Ha KY, Park KS, Kim SI and Kim YH: Does bisphosphonatebased anti-osteoporosis medication affect osteoporotic spinal fracture healing? Osteoporos Int 27: 483-488, 2016.

9. Su FM, Chen YC, Cheng TT, Lin WC and Lui CC: Is raloxifene associated with lower risk of mortality in postmenopausal women with vertebral fractures after vertebroplasty?: A hospital-based analysis. BMC Musculoskelet Disord 16: 209, 2015.

10. Lazzari AA, Dussault PM, Thakore-James M, Gagnon D, Baker E, Davis SA and Houranieh AM: Prevention of bone loss and vertebral fractures in patients with chronic epilepsy - antiepileptic drug and osteoporosis prevention trial. Epilepsia 54: 1997-2004, 2013.

11. Chen AT, Cohen DB and Skolasky RL: Impact of non-operative treatment, vertebroplasty, and kyphoplasty on survival and morbidity after vertebral compression fracture in the medicare population. J Bone Joint Surg Am 95: 1729-1736, 2013. 
12. Chen HG, Zhang Z, Liang HP, Kong QZ, Chen JH and Zhou Y: Clinical observation of effects and complications of the mid-stage in treating osteoporotic vertebral compression fracture with percutaneous kyphoplasty. Zhongguo Gu Shang 23: 743-745, 2010 (In Chinese)

13. Ma XL, Xing D, Ma JX, Xu WG, Wang J and Chen Y: Balloon kyphoplasty versus percutaneous vertebroplasty in treating osteoporotic vertebral compression fracture: Grading the evidence through a systematic review and meta-analysis. Eur Spine J 21: 1844-1859, 2012.

14. Tseng YY, Su CH, Lui TN, Yeh YS and Yeh SH: Prospective comparison of the therapeutic effect of teriparatide with that of combined vertebroplasty with antiresorptive agents for the treatment of new-onset adjacent vertebral compression fracture after percutaneous vertebroplasty. Osteoporos Int 23: 1613-1622, 2012.

15. Gu YF, Li YD, Wu CG, Sun ZK and He CJ: Safety and efficacy of percutaneous vertebroplasty and interventional tumor removal for metastatic spinal tumors and malignant vertebral compression fractures. AJR Am J Roentgenol 202: W298-W305, 2014

16. Tomé-Bermejo F, Piñera AR, Duran-Álvarez C, LópezSan Román B, Mahillo I and Alvarez L: Identification of risk factors for the occurrence of cement leakage during percutaneous vertebroplasty for painful osteoporotic or malignant vertebral fracture. Spine 39: E693-E700, 2014.

17. Lai PL, Tai CL, Chu IM, Fu TS, Chen LH and Chen WJ: Hypothermic manipulation of bone cement can extend the handling time during vertebroplasty. BMC Musculoskelet Disord 13: 198, 2012.

18. Boger A, Benneker LM, Krebs J, Boner V, Heini PF and Gisep A: The effect of pulsed jet lavage in vertebroplasty on injection forces of PMMA bone cement: An animal study. Eur Spine J 18: 1957-1962, 2009.

19. Zhu SY, Zhong ZM, Wu Q and Chen JT: Risk factors for bone cement leakage in percutaneous vertebroplasty: A retrospective study of four hundred and eighty five patients. Int Orthop 40: $1205-1210,2016$

20. Wang CH, Ma JZ, Zhang CC and Nie L: Comparison of high-viscosity cement vertebroplasty and balloon kyphoplasty for the treatment of osteoporotic vertebral compression fractures. Pain Physician 18: E187-E194, 2015.

21. Zhang L, Wang J, Feng X, Tao Y, Yang J, Wang Y, Zhang S, Cai J and Huang J: A comparison of high viscosity bone cement and low viscosity bone cement vertebroplasty for severe osteoporotic vertebral compression fractures. Clin Neurol Neurosurg 129: $10-16,2015$.
22. Langley GB and Sheppeard H: The visual analogue scale: Its use in pain measurement. Rheumatol Int 5: 145-148, 1985.

23. Park SW, Shin YS, Kim HJ, Lee JH, Shin JS and Ha IH: The dischargeable cut-off score of Oswestry Disability Index (ODI) in the inpatient care for low back pain with disability. Eur Spine J 23: 2090-2096, 2014.

24. Disch AC and Schmoelz W: Cement augmentation in a thoracolumbar fracture model: Reduction and stability after balloon kyphoplasty versus vertebral body stenting. Spine 39: E1147-E1153, 2014

25. Chen C, Li D, Wang Z,Li T, Liu X and Zhong J: Safety and efficacy studies of vertebroplasty, kyphoplasty, and mesh-container-plasty for the treatment of vertebral compression fractures: Preliminary Report. PLoS One 11: e0151492, 2016.

26. Hu X, Zhai X and Hirt T: A new concept for more biocompliant bone cements for vertebroplasty and kyphoplasty. Macromol Biosci 9: 195-202, 2009.

27. Hernández L, Parra J, Vázquez B, Bravo AL, Collía F, Goñi I, Gurruchaga $M$ and San Román J: Injectable acrylic bone cements for vertebroplasty based on a radiopaque hydroxyapatite. Bioactivity and biocompatibility. J Biomed Mater Res B Appl Biomater 88: 103-114, 2009.

28. Shen Y, Ren H, Zhang Y, Zhi X, Ding W, Xu J and Yang D: Correlative factor analysis of complications resulting from cement leakage after percutaneous kyphoplasty in treatment of osteoporotic vertebral body compression. Zhongguo Xiu Fu Chong Jian Wai Ke Za Zhi 24: 27-31, 2010 (In Chinese).

29. Bolander JE, Choi S and Duddukuri SR: Fracture of fiber-reinforced cement composites: Effects of fiber dispersion. Int J Fract 154: 73-86, 2008.

30. Hulme PA, Boyd SK and Ferguson SJ: Regional variation in vertebral bone morphology and its contribution to vertebral fracture strength. Bone 41: 946-957, 2007.

This work is licensed under a Creative Commons Attribution-NonCommercial-NoDerivatives 4.0 International (CC BY-NC-ND 4.0) License. 